Discussion Paper No. 08-043

\title{
Heterogeneous Labour Markets in a Microsimulation-AGE Model: Application to Welfare Reform in Germany
}

Stefan Boeters and Michael Feil

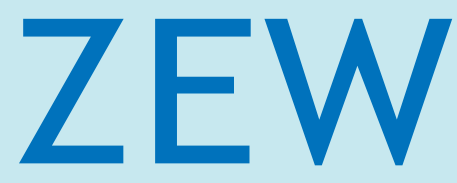

Zentrum für Europäische Wirtschaftsforschung $\mathrm{GmbH}$

Centre for European

Economic Research 
Discussion Paper No. 08-043

\section{Heterogeneous Labour Markets in a Microsimulation-AGE Model: Application to Welfare Reform in Germany}

Stefan Boeters and Michael Feil

Download this ZEW Discussion Paper from our ftp server:

ftp://ftp.zew.de/pub/zew-docs/dp/dp08043.pdf

Die Discussion Papers dienen einer möglichst schnellen Verbreitung von neueren Forschungsarbeiten des ZEW. Die Beiträge liegen in alleiniger Verantwortung der Autoren und stellen nicht notwendigerweise die Meinung des ZEW dar.

Discussion Papers are intended to make results of ZEW research promptly available to other economists in order to encourage discussion and suggestions for revisions. The authors are solely responsible for the contents which do not necessarily represent the opinion of the ZEW. 


\section{Nicht-technische Zusammenfassung}

Wir untersuchen die Auswirkungen von Steuer-Transfer-Reformen in einem konsistent gekoppelten Mikro-Makro-Modell mit heterogenen Arbeitsmärkten. Das Modell umfasst drei Qualifikationstypen, die in der Produktion unvollständig substituierbar sind. Die empirisch geschätzten Substitutionsbeziehungen zwischen diesen Qualifikationstypen werden durch nicht-separierbare, mehrstufige CES-Funktionen abgebildet. Kollektive Lohnverhandlungen in den Arbeitsmarktsegmenten mit geringer und mittlerer Qualifikation kontrastieren mit einem Markt vollständiger Konkurrenz bei den Hochqualifizierten. Sowohl die flexible Substitutionsstruktur als auch die Heterogenität in den Arbeitsmarkt-Institutionen wirken sich auf die Simulationsergebnisse aus, wobei den Arbeitsnachfrage-Elastizitäten eine herausgehobene Rolle zukommt.

Wir simulieren mit diesem Modell eine Reform des deutschen Steuer-TransferSystems, bei der das Arbeitsangebot der Niedrigqualifizierten durch eine Kombination von geringeren Sozialhilfe-Zahlungen (ALG II) und einer reduzierten Transferentzugsquote stimuliert wird. Die Modellergebnisse sind über alle untersuchten Modellvarianten robust: Partizipationseffekte sind positiv und quantitativ erheblich. Sie sind am stärksten für Singles, während Paarhaushalte weniger stark reagieren. Die Auswirkungen auf die durchschnittliche Arbeitszeit sind klein, so dass der totale Arbeitsangebotseffekt durch die Veränderung in der Partizipationsquote dominiert wird.

Im allgemeinen Gleichgewicht fallen die Löhne aller Qualifikationsgruppen, am stärksten bei den Geringqualifizierten. Dies wirkt auf das Arbeitsangebot zurück und schwächt die Arbeitsangebotseffekte verglichen mit dem partiellen Gleichgewicht ab. Wegen der relativ niedrigen Arbeitsnachfrageelastizitäten gehen Lohnrückgänge mit einer geringeren Lohnquote einher, was wiederum zu einer Verschiebung in der Nachfragestruktur von Konsum zu Investitionen führt. Trotz einer Steigerung des BIP um mehr als ein Prozent hat die Steuer-Transfer-Reform keine positiven Auswirkungen auf das öffentliche Budget. Dies liegt daran, dass die Verschiebung in der funktionalen Einkommensverteilung zu deutlichen Steuerausfällen führt.

Die Konsequenzen eines Übergangs von kollektiven Lohnverhandlungen auf einen Arbeitsmarkt vollständiger Konkurrenz für die Hochqualifizierten bleiben im Wesentlichen auf dieses Arbeitsmarktsegment selbst beschränkt. Bei vollständiger Konkurrenz entfallen die lohnreduzierenden Konsequenzen einer höheren Steuerprogression und einer Verschlechterung der gewerkschaftlichen Rückfallposition, so dass der Lohnrückgang und die Beschäftigungssteigerung geringer sind als bei kollektiven Lohnverhandlungen. 


\section{Non-technical summary}

We explore the consequences of implementing heterogeneous labour markets in a consistently linked micro-macro model used to analyse tax and transfer reforms. Three skill types of labour are distinguished, which are imperfect substitutes in the production process. They are implemented in a set-up that uses non-separable, nested CES functions in order to allow for an unrestricted matrix of elasticities of substitution within the production function. We combine wage bargaining for the low and medium skilled with a perfectly competitive labour market for the high skilled. Both the flexible substitution structure and the heterogeneity in labour market institutions play a role in the results, but labour demand elasticities turn out to be the most important drivers.

We use the model to simulate a reform of the German transfer system that stimulates labour supply at the lower end of the wage distribution by combining lower basic social assistance payments and a lower transfer withdrawal rate. Qualitatively, the results are fairly robust. In all model variants considered, participation effects are positive and considerably large. They are most pronounced for singles; spouses in couples are less affected. By contrast, the effects on the average working time are small, so that changes in overall labour supply are dominated by the participation response.

In general equilibrium, wages fall for all skill groups, but most significantly for the low skilled. This produces feedback and dampens labour supply reactions compared to a partial analysis. Due to relatively low labour demand elasticities, wage drops translate into a lower share of labour, which in turn produces a switch from consumption to investment in the spending pattern. Although GDP increases by more than one percent, the welfare reform, in isolation, is not self-financing because the shift in functional income distribution causes considerable tax revenue losses.

The consequences of the switch from wage bargaining to competitive wage formation for the high skilled are concentrated on this very skill group. In a competitive labour market setting, the wage-reducing effects of higher tax progressivity and a deterioration of the fallback position of trade unions are absent. Therefore wage drops are less pronounced and employment gains are lower compared with collective wage bargaining. 


\title{
Heterogeneous Labour Markets in a Microsimulation-AGE Model: Application to Welfare Reform in Germany
}

\author{
Stefan Boeters ${ }^{a, *}$, Michael Feil ${ }^{b}$ \\ ${ }^{a}$ CPB, Netherlands Bureau for Economic Policy Analysis, Den Haag \\ ${ }^{b}$ IAB, Institute for Employment Research, Nürnberg
}

June 2008

\begin{abstract}
Labour market reforms that are designed to stimulate labour supply at the lower end of the wage distribution can never be precisely restricted to affect only the target group. Spillovers to and feedback from other segments of the labour market are unavoidable and may counteract the direct effects of the reform. An adequate representation of heterogeneous labour markets becomes therefore an important issue for the assessment of reforms. We analyse the possible interactions between labour market segments in a combined, consistent microsimulation-AGE model with a flexible representation of substitution possibilities and different wage-forming regimes. We look at a stylised reform and find labour-demand cross-price elasticities between the low and medium skilled to be the main drivers of the results. Interaction with the high-skilled segment is less pronounced.
\end{abstract}

Keywords: Applied general equilibrium model, microsimulation, discrete working time choice, heterogeneous labour markets, labour market reform

JEL Code: D58, J22, J51

\footnotetext{
*Corresponding author: Stefan Boeters, CPB, P.O. Box 80510, NL-2508 GM Den Haag, e-mail: s.boeters@cpb.nl. We thank Timo Baas, Markus Clauss, Rob Euwals, Nicole Gürtzgen and Stefanie Schubert for helpful comments.
} 


\section{Introduction}

Many European countries are engaged in a continuous process of reforming their labour market institutions and the tax and welfare system. The EU countries even committed themselves to explicit labour force participation targets in the context of the "Lisbon strategy" (Gelauff and Lejour, 2006). Labour market reforms particularly focus on the low-skilled segment of labour supply and demand (for an overview see Orsini, 2005). This segment is crucial for the overall labour market performance, as unemployment rates are highest in this segment and participation is below average. At the same time we observe particularly difficult conditions for employment gains here because negative demand effects from skill-biased technological change and shifting world trade patterns are further complicated by supply disincentives resulting from the tax and transfer schemes. The situation is often described as a "poverty trap", caused by the small (or even negative) difference between the welfare benefits for the non-employed and net earnings at low wage levels, and a high transfer withdrawal rate.

Concrete policy proposals that aim at an amelioration of this situation face two main difficulties. First, those who are not able to work cannot compensate reductions in the welfare payments by more intense search on the labour market. For this group income losses are considered to be unacceptable. Second, lower transfer withdrawal rates usually lead to windfall profits for those workers who are in the respective income bracket and already active in the labour market. These windfall profits and the ensuing tax revenue losses can be large enough to render the reforms infeasible from a public budget point of view. Due to this latter problem we cannot restrict ourselves to the low-skilled segment if we engage in an ex-ante evaluation of labour market reforms. The other segments must be taken into account as well, and the way we model the labour markets for the high skilled can make a difference for the overall assessment of concrete reform proposals.

In general, the analysis of encompassing labour market reforms requires a model that includes the most important micro and macro features of the labour market. We think that this can only be achieved in a convincing way if we choose a micromacro approach that combines microsimulation and general equilibrium feedback mechanisms. In particular, we take PACE-L, an applied general equilibrium (AGE) 
model with labour market focus as our point of departure and add a microsimulation module based on the German Socio-Economic Panel (GSOEP) with about 3000 households. (See Arntz et al., 2008, for a more comprehensive discussion of this approach.)

Such an integrated approach can be contrasted with pure microsimulation studies on the one hand and pure AGE models on the other. The usual labour market application of microsimulation (for an overview see Gupta and Kapur, 2000) combines individual micro data with a discrete labour supply decision modelled in the tradition of van Soest (1995). In most cases, however, this approach remains confined to the micro level and cannot address the macro issues of endogenously adjusting wages, unemployment and the public budget. ${ }^{1}$ If we approach the analysis from the macro end, we deal with models in the AGE tradition (Shoven and Whalley, 1984) that combine a standard AGE setup with a somewhat more detailed labour market module (Hutton and Ruocco, 1999; Graafland et al., 2001; Böhringer et al., 2005). A common problem in this setup is the distinction between the intensive and extensive margin of labour supply. Even if this problem is solved in principle, as in Graafland et al. (2001), the model reacts sensitively to the structural assumptions of the calibration procedure (Arntz et al., 2006).

Examples of a full micro-macro linkage in applied labour market research are rare. Two exceptions are Müller (2004) and Aaberge et al. (2004), but the focus of those studies is considerably different from ours. Müller (2004) simulates versions of a basic income in Switzerland, and Aaberge et al. (2004) analyse the fiscal consequences of ageing in the presence of an adjusting labour market in Norway. In the field of international trade and development economics, in contrast, the integrated micro-macro approach is more established (Bourguignon et al., 2005; Cororaton and Cockburn, 2007; Rutherford et al., 2005). An important difference between analysis of trade policy and labour market reforms should be noted. In the trade literature the initial shock is on the macro level (trade regime shifts), and the micro consequences are analysed (income of individual households). By contrast, in the labour market analysis of our paper, the initial shock is at the micro level, and macro variables (wage and unemployment reactions) are among the outcomes of interest.

\footnotetext{
${ }^{1} \mathrm{~A}$ recent example for Germany that does take involuntary unemployment into account is Bargain et al. (2005).
} 
In our simulation exercises, we study the interaction among heterogeneous labour markets in the context of a reform that is targeted at the low-income segment. In particular, we simulate a reform that increases labour supply incentives by a simultaneous reduction of benefits and transfer withdrawal rate for low wage incomes. We explore to what extent and through which mechanisms the representation of the markets for skills and the formulation of the production structure matter in such a setting. This includes a departure from our previous approach ${ }^{2}$ (Böhringer et al., 2005, Arntz et al., 2008): We split labour into three instead of two skill groups, which together with physical capital and intermediate inputs are combined in a flexible production function. In addition, we model the labour market for high-skilled workers as perfectly competitive while remaining with the wage-bargaining formulation for the medium and low skilled.

Working with three types of labour has the advantage that we can calibrate our model to estimates based on the same decomposition of labour, which has become standard in empirical work (e.g. Fitzenberger, 1999, or Falk and Koebel, 2001). Switching from a two-level nested CES production function to a flexible functional form is in line with the econometrics of factor demand, where functions such as Translog or Diewert are typically used. In addition, a separate labour market for the high skilled gives us leeway to exclude them from collective bargaining. Our simulation results show that both the implementation of empirically founded substitution patterns between the different skill groups and the labour market institutions for the high skilled affect the macroeconomic outcomes of the reform. In terms of quantitative significance, the most action is in the interaction between the low and medium skilled labour market segment. The repercussions from the high-skilled segment are less pronounced, because the relevant cross-price elasticities are low. This is also the reason that the choice of the labour-market regime for the high skilled has only small spillover effects to the other labour market segments.

The remainder of this paper is organised as follows. In Section 2, we describe the two building blocks of the model - the discrete choice labour supply module and

\footnotetext{
${ }^{2}$ An application of this approach to recent labour market reforms in Germany can be found in Franz et al. (2007). That study places special focus on a precise representation of the current tax and transfer schedule, whereas in our paper, we remain with a stylised version to make a more methodological point.
} 
the AGE framework - and our way of linking them. Section 3 describes our implementation of the three skill groups and heterogeneous labour market institutions in the model. Section 4 reports the results of the comparative scenario analysis. To put the results in perspective, we compare the main model version with a partial labour supply model and with a uniform wage-bargaining regime for all skill groups. Section 5 provides further sensitivity analysis with respect to the labour demand calibration and capital mobility. In Section 6, we draw conclusions and sum up. An appendix provides additional information about the estimation results of the discrete-choice model, the German tax and transfer system and the labour demand calibration.

\section{The modules of the model}

We analyse labour market reforms in an integrated micro-macro model. The micro module consists of a discrete choice (DC) labour supply set-up for heterogeneous households. The macro module is made up of a multi-sectoral AGE model of an open economy with wage bargaining. In this section, we present the two modules individually, and then discuss the links between them, which produce consistent feedback loops. A more extensive discussion of the micro-macro set-up can be found in Arntz et al. (2008).

\subsection{Labour supply: a logit discrete-choice approach}

The labour supply analysis in our model is based on the microsimulation model for Germany by Buslei and Steiner (1999). This model combines a calculator for the household income under the current German tax and transfer system (see Appendix A.3) with a DC labour supply estimation of the van Soest (1995) type. Using information from the German Socio-Economic Panel (GSOEP), we construct labour supply options (which combine the respective amounts of income and leisure) for all households: For married males, there are three labour supply options, whereas for all other individuals (married women, single females and single males) there are five. This corresponds to the empirical distribution of labour supply behaviour. The options are summarised in Table 9 in the appendix. 
According to the DC setup, the utility of each option is a combination of a deterministic part, $\bar{U}$, that depends on a vector of individual and alternative-specific characteristics, $x_{j, k}$, and an additive stochastic term. For household $j$ of type $i$ we then have

$$
U_{i}\left(x_{j, k}\right)=\bar{U}_{i}\left(x_{j, k}\right)+\varepsilon_{j, k} .
$$

The distinctive feature of the logit approach is that the error term, $\varepsilon_{j, k}$, is assumed to be independently standard extreme-value distributed. Under this assumption there is an explicit formula for the probability of preferring option $k$ over all other options $l \neq k$ from a set $m$ (McFadden, 1974):

$$
P\left(U_{i}\left(x_{j, k}\right)>U_{i}\left(x_{j, l}\right)\right)=\frac{\exp \left(\bar{U}_{i}\left(x_{j, k}\right)\right)}{\sum_{m} \exp \left(\bar{U}_{i}\left(x_{j, m}\right)\right)}, \quad \forall l \neq k
$$

In our specification, the argument vector, $x_{j, k}$, of the deterministic part of the utility function, $\bar{U}_{i}$, includes the logs of disposable income and weekly hours of leisure for men and women:

$$
x_{j, k}=\left(\log \left(C_{i}\left(h_{j, k}^{f}, h_{j, k}^{m}\right)\right), \log \left(T-h_{j, k}^{f}\right), \log \left(T-h_{j, k}^{m}\right)\right),
$$

where $h^{f}$ and $h^{m}$ are the working time of the spouses and $T$ is time endowment. We follow van Soest (1995) in assuming a quadratic utility function with $A_{i}$ and $\beta_{i}$ as parameters that capture the quadratic and linear terms:

$$
\bar{U}_{i}\left(x_{j, k}\right)=x_{j, k}^{\prime} A_{i} x_{j, k}+\beta_{i}^{\prime} x_{j, k} .
$$

The parameters include interactions between leisure, income and a number of household characteristics (age, dummy for citizenship, East Germany, handicaps and children in certain age brackets). These interactions account for differences in the preferences of households for particular hours-of-work options. In addition, we capture fixed costs of working by constant terms: For singles we include a constant for all positive hours categories; for couples, there are two constants, one for positive working hours on the part of the woman, the other for both spouses working. We estimate the coefficients separately for couples, female singles and male singles. A complete list of regressors and the detailed estimation results can be found in Appendix A.2.

Given the individual parameters of the utility functions and the disposable incomes for the pre and post-reform situations, we can proceed with simulating labour 
supply reactions to policy changes. Inserting disposable incomes in the utility function, we arrive at positive probabilities for each labour supply option. We implement a simulation method proposed by Duncan and Weeks (1998, see also Creedy and Kalb, 2005), which exploits the fact that we have information about the choices of households in the initial situation. This can be used to transform the utility evaluations of disposable income into conditional probabilities. We draw random numbers from the extreme-value distribution, and retain only those that are consistent with the actual choice of the respective household. In the subsequent simulation, with changed disposable incomes for the different labour supply options, the optimal choice will change for a subset of these random numbers. In the initial situation, each household chooses exactly one option, whereas in the post-reform situation, we end up with a genuine probability distribution over all options.

\subsection{The AGE framework}

The labour supply module is embedded in an applied general equilibrium model of Germany ("PACE-L"). In this section, we only sketch the general parts of the model. The wage determination module of PACE-L is singled out in Section 3.2. An extensive, algebraic model description and a summary of the data sources used for calibration can be found in Böhringer et al. (2005). ${ }^{3}$

\section{Firms}

In each of seven aggregate production sectors, a representative firm produces a homogeneous output. The production function is of the nested constant-elasticityof-substitution (CES) type, combining intermediate inputs, capital and labour of the three skill types (for details, see Section 3.1). Each individual firm is assumed to be small in relation to its respective sector. All firms in one sector interact through monopolistic competition, so that firms can exploit market power in their individual market segment. Cost minimisation yields demand functions for the primary factors at the sectoral level and corresponding uncompensated (own and cross) price elasticities for labour. Capital is mobile across sectors, and the market for capital is perfectly competitive. In the simulations in Section 4, we additionally assume that

\footnotetext{
${ }^{3}$ An updated, complete model description, which includes the changes implemented for this paper, is available upon request.
} 
capital is internationally immobile, which reflects a short- to medium-run model horizon.

\section{Private households}

We distinguish about 3000 individual worker households with flexible labour supply, one residual worker household with fixed labour supply, and a capitalist household. The households captured by the microsimulation model include all households with flexible time allocation and observable hours of work, which is about $60 \%$ of total labour supply. Pensioners, students, women on maternity leave, civil servants and the self-employed are excluded from the microsimulation model. In the general equilibrium model, they are represented by an aggregate residual household with fixed labour supply. At the same time, the residual household makes up for the difference in structure between the micro data set and the national accounts. The capitalist household receives all capital and profit income. Capitalists decide over consumption and investment according to the approach of Ballard et al. (1985). Their utility function is calibrated to empirical saving elasticities. Worker households, by contrast, do not save. The structure of consumption is assumed to be identical across all households. Aggregate consumption is distributed among 12 different consumption goods according to a CES function.

\section{Government}

The main focus of the model in this paper is on the complex tax and transfer system for private households, whose budget constraints are calculated in a special programme module (see Appendix A.3). Apart from taxes and transfers for private households, the government collects a uniform capital input tax, a profit tax, an output tax in production and a differentiated consumption tax. The government budget contains the revenue from all these taxes, the public purchases of goods, and the balance of payments surplus or deficit. The income tax (on labour and domestic capital income) includes an endogenous multiplier that is adjusted so that counterfactual scenarios are made revenue-neutral.

\section{Foreign Trade}

Domestically produced goods are converted into specific goods destined for the domestic market and the export market through a constant-elasticity-of-transformation function. According to the small-open-economy assumption, export and import 
prices in foreign currency are not affected by the behaviour of the domestic economy. Analogously to the export side, we adopt the Armington assumption of product heterogeneity for the import side. A CES function characterises the choice between imported and domestically produced varieties of the same good. The Armington good enters intermediate and final demand. Foreign closure of the model is warranted through the balance-of-payments constraint.

\subsection{Linking the microsimulation and AGE modules}

The microsimulation module by its very nature contains a large number of households and detailed equations for the budget constraints at all labour supply options and labour market states (employed, unemployed). Literally integrating this into the AGE model would generate a lot of slack, i.e. equations that are only of minor importance for the general equilibrium reactions. We therefore opt for a model setup where the two modules are kept separate and iterated until we arrive at a global solution. In policy simulations, such as those in Section 4, we start with the modified rules of the tax and transfer system and first simulate labour supply changes under the assumption of constant wages and unemployment rates. The resulting labour supply is aggregated (by skill type) and transferred to the AGE model, which is solved under the assumption of a fixed labour supply. This results in changes in wages and unemployment rates, which are fed back to the labour supply module for the next iteration. This proceeds until the two model modules converge. ${ }^{4}$

Three aspects of the linkage set-up deserve a closer look. First, in aggregating labour supply, we use efficiency weighting. That is, labour supply in hours is weighted by the respective wage rate of the initial situation. It is assumed that all individual wage rates (within a skill group) move in parallel, so adjustment of the weights during the iterations is not an issue. Efficiency weighting corresponds to the assumption that all labour of the same skill type is perfectly substitutable, except for the efficiency factor derived from the empirical wages. Second, when we move from

\footnotetext{
${ }^{4}$ As a stopping criterion, we use a change in the unemployment rate between two subsequent iterations of less than 10e-5. Usually, the model converges to this precision within less than ten iterations. Remarkably, the convergence in aggregate labour supply is very fast, while unemployment rates are more volatile, showing oscillating convergence and overshooting their final value in the first iteration by about 100 per cent.
} 
the AGE module to the labour supply module, individual unemployment rates need to be adjusted. Unemployment probabilities differ by household type (42 household types differentiated by household composition and skill level), but are equal within each household type. As the relative labour supply of the household types changes during the iterations of the model, a change in the overall unemployment rate (as an output of the AGE module) does not simply translate into proportional changes in individual unemployment rates, but must be numerically adjusted. This is done in every iteration step at the transition from the AGE to the labour supply module. Third, in the AGE model with constant labour supply, an assumption is required about the taxation of income changes that are caused by the endogenously adjusting wage. As the individual tax rates are not available in the AGE model, we leave these income changes untaxed in the intermediate iterations of the model. The exact split into after-tax income and tax revenue is determined only in the next run of the labour supply module.

\section{Implementing three skill groups in the MS-AGE model}

\subsection{Production structure: NNCES implementation}

Earlier versions of PACE-L (Böhringer et al., 2005, Arntz et al., 2008) work with a conventional separable nested CES function to represent production. Value added is split into low-skilled labour and an aggregate of high-skilled labour and capital in a first stage. In a second stage, capital and high-skilled labour are separated. Such a set-up can account for stylised patterns of substitution elasticities, in particular the well known capital-skill complementarity (Fallon and Layard, 1975), but it is not flexible enough to represent full matrices of estimated cross price elasticities.

Restrictions through a structure of nested separable CES functions become the more severe the more input factors we discriminate. If we extended the structure of Böhringer et al. (2005) and split up high-skilled labour in a medium and a highskilled component, we would end up with four free parameters (elasticities of substitution at various levels of the production tree) to be calibrated. However, a fully flexible structure, such as the one estimated by Falk and Koebel (1997), features at 
Figure 1: NNCES set-up of production function

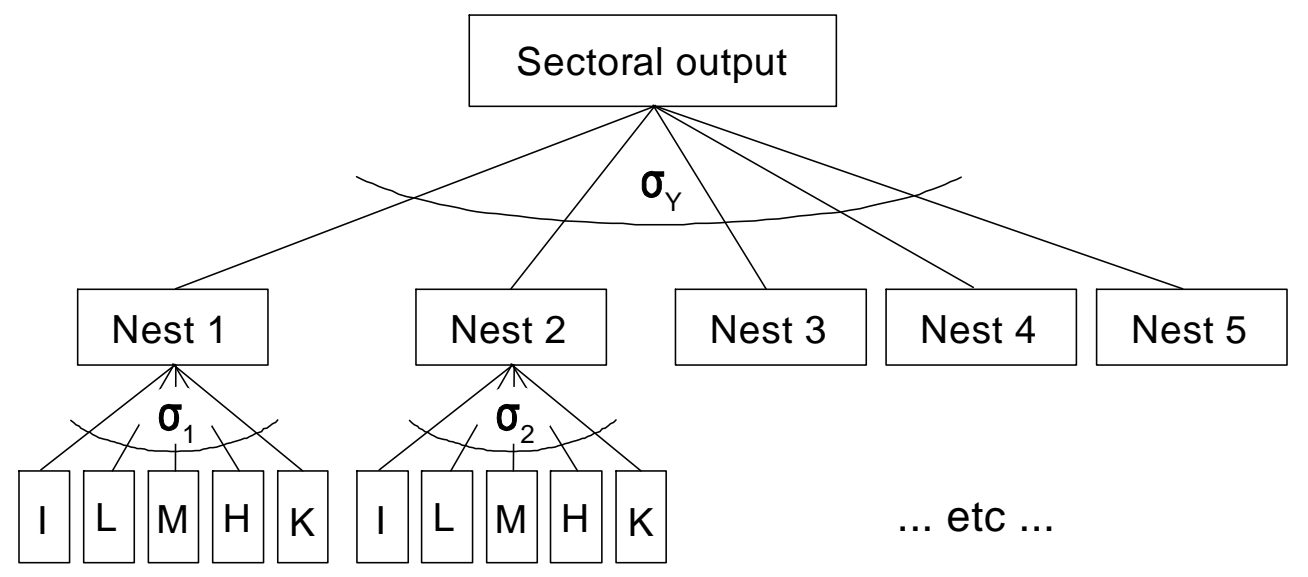

least 10 independent elasticities of substitution: a $5 \times 5$ matrix where 10 elements are mirror images of the opposite side and 5 elements are linearly dependent on the other entries in the same row or column.

The NNCES (non-separable, nested CES) approach to production function calibration (Pollak and Wales, 1987, Perroni and Rutherford, 1995, 1998) increases the flexibility of the nested CES framework through an extension to more generic forms. Other flexible forms known from econometric tradition (Translog or Diewert) can locally represent arbitrary production or cost functions as well, but they typically do not exhibit global regularity (the corresponding cost function must be non-decreasing and concave in prices). This can cause computational problems in AGE models (Perroni and Rutherford, 1995).

The basic idea behind the NNCES function is that each factor of production can enter the production function at more than one single place (therefore "nonseparable"). A typical set-up can be seen in Figure 1: Sectoral output is decomposed into five sub-nests, each of which then in turn contains input from all factors: intermediate inputs ("I"), the three skill types ("L", "M", "H") and capital ("K"). Flexibility is increased not only by a larger number of elasticity parameters (six), but also because the split of each production factor into the individual sub-nests can be chosen freely.

Actually, the problem is now the other way around. Instead of too few para- 
meters, we now have too many. We face the ten exogenous elasticities with 26 free parameters at hand (six elasticities and four free share parameters for each factor). To resolve the resulting indeterminacy, it has been proposed to restrict certain elasticities to zero or one (Pollak and Wales, 1987) or to add a penalty function. We follow a suggestion by Rutherford and penalise dispersion of input factors across several nests as well as large values of the elasticities of substitution. The approach can be expressed algebraically as follows:

$$
\begin{aligned}
\max & \sum_{n, i}\left(\theta_{n}^{i}\right)^{2}-\left(\sigma_{Y}\right)^{2}-\sum_{n}\left(\sigma_{n}\right)^{2} \\
\text { s.t. } \quad \eta_{i j} / \theta_{j}^{Y} & =\sigma_{Y}+\sum_{n}\left(\sigma_{n}-\sigma_{Y}\right) \frac{\theta_{n}^{i} \theta_{n}^{j}}{\theta_{n}^{Y}} \\
\theta_{n}^{Y} & =\sum_{i} \theta_{i}^{Y} \theta_{n}^{i} \\
1 & =\sum_{n} \theta_{n}^{i}
\end{aligned}
$$

where $i$ and $j$ are indexes for the factors of production and $n$ is an index for the nests at the intermediate level ("Nest 1" etc. in Figure 1). The $\theta_{n}^{i}$ are the shares of the individual nests in the total amount of factor $i, \theta_{n}^{Y}$ is the share of the respective nest in total sectoral output. The own and cross price elasticities, $\eta_{i j}$, as well as the aggregate value shares, $\theta_{i}^{Y}$, are exogenous to the calibration. $\sigma_{Y}$, the $\sigma_{n}$ 's and the $\theta_{n}^{i}$ 's must be determined by minimising the penalty function. Appendix A.4 gives the details of the labour demand elasticities, $\eta_{i j}$, to be calibrated and an example of the calibration results in one sector.

\subsection{Competitive labour markets vs. collective wage bargain- ing}

We choose a flexible, parametric set-up for the model, which allows us to choose between a competitive labour market and sectoral wage bargaining separately for each skill group. Our default setting for the simulations in Section 4 is wage bargaining for the low and medium skilled and a competitive labour market for the high skilled. In the latter case labour market equations are straightforward. The 
competitive wage does the job of equalising supply and demand. Wage bargaining, in contrast, requires a more in-depth explanation.

In the wage bargaining regime, wages are determined by sector and skill group specific negotiations between an employers' association and a trade union. The bargaining outcome is generated through the maximisation of a Nash function, which includes the objective functions of both parties and their respective fallback options. We adopt the "right to manage" approach: Parties bargain over wages, and firms determine labour demand on the basis of the bargained wage. On the part of the trade unions, we choose an "insider" objective function: value of a job minus the value of the outside option. The latter in turn is composed of two components, associated with the chances of finding a job in another sector or remaining unemployed. The values of labour market states are recursively determined as weighted averages of incomes in the case of employment and unemployment, where weights are computed from the transition probabilities between employment and unemployment (see Pissarides, 1990, for an overview of the search-and-matching approach).

When linking the wage bargaining equations to the microsimulation module, we assume that all individual households are uniformly represented by the trade union. Marginal tax rates and the values of employment and unemployment are calculated as (hours-weighted) averages over all households and labour supply options of the respective skill group. In turn, the wage that results from bargaining in general equilibrium is used to derive the income positions of all households in all possible labour market states. Here, we use the numerically approximated values of the marginal effective tax rate (see Appendix A.3). The three labour markets are balanced by aggregating on the demand side over sectors and on the supply side over households of the respective type. We assume that, with respect to households types, the structure of labour demand is uniform across sectors.

In the wage-bargaining regime, wages respond to reforms in the tax and transfer system through two different channels. First, the reforms change the marginal burden of the total tax and transfer system (either through an explicit change of tax rates or through lower transfer withdrawal rates). This bears on the bargaining outcome through the average skill-specific effective marginal tax rates. However, the effect of a specific reform on the average marginal tax rate is in most cases not clear a priori because the marginal burden increases for some individuals while it decreases for 
others. As a benchmark, we know that with a constant average tax rate, an increase in the effective marginal tax rate raises the degree of tax progression, which leads to wage moderation on the part of the unions (Koskela and Vilmunen, 1996). Second, reforms of the transfer system reduce expected income when being unemployed (and thus the fall-back position of unions) in two ways: directly through lower transfer payments and - if they succeed in stimulating labour supply - indirectly through a higher probability of unemployment (at given labour demand). This puts additional pressure on wages.

\section{Policy simulations: welfare reform with hetero- geneous labour markets}

We now apply the model described in Sections 2 and 3 in order to simulate a social welfare reform that is designed to stimulate labour market participation of lowincome workers. We first explain the before and after-reform situations and then simulate the labour market effects of the reform in different model versions. We are mainly interested in the version including three skill types and heterogeneous labour markets. However, to put the results into perspective, we complement this version with two variants: (1) a partial equilibrium model, which isolates the labour supply effects and allows us to identify the extent of the general equilibrium feedback, and (2) a version where we have wage bargaining on all labour markets, which highlights the effects of the labour market institutions for the high skilled.

\subsection{Status-quo system and reform scenario}

Germany's welfare system is particularly suited for our demonstration purposes since it produces strong labour market disincentives of the type we discussed in the introduction. ${ }^{5}$ The benefit level is widely considered too generous from an incentive

\footnotetext{
${ }^{5}$ In 2005 the German social benefit system underwent a considerable change through the socalled "Hartz IV" reform. Work-related and work-independent benefits were combined into one benefit, the basic job seekers allowance (Unemployment Benefit II). The disincentives at the lower end of the labour market were not changed much through this reform (Franz et al., 2007). Therefore, we remain with the institutional setting and the terminology of the pre-Hartz situation.
} 
point of view, and transfer withdrawal results in effective marginal tax rates that are close to 100 per cent at the bottom of the income distribution.

Figure 2: Income function of a single without children

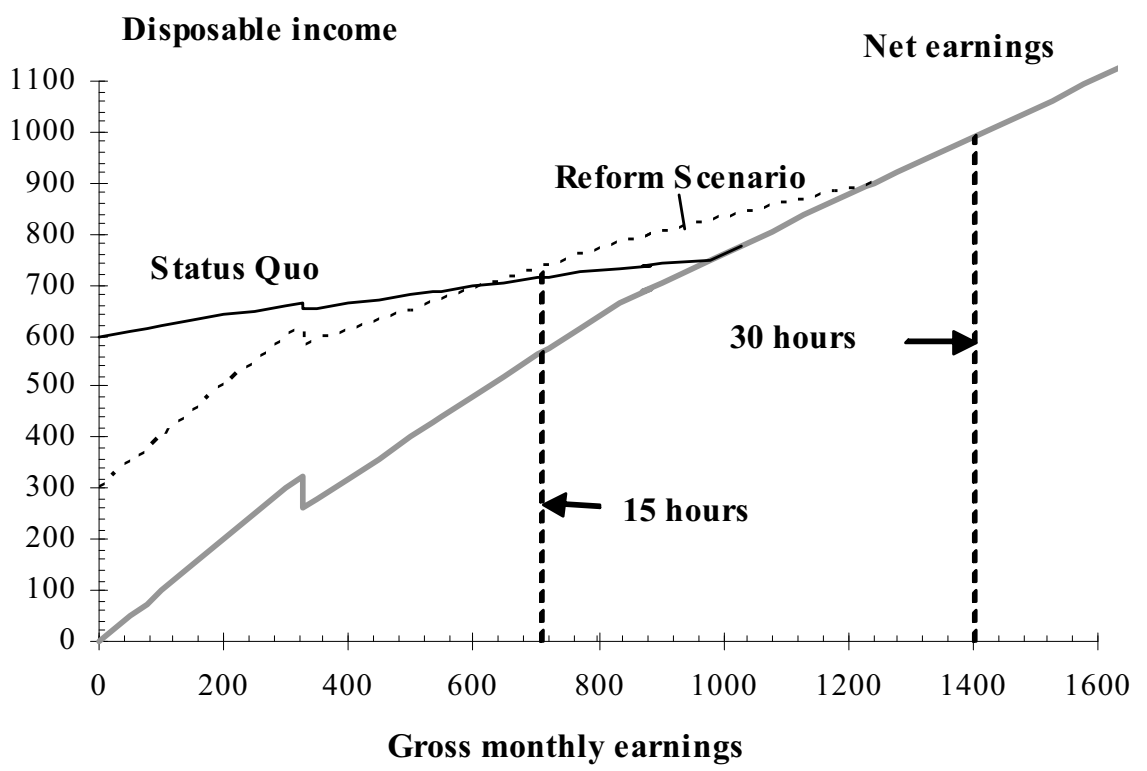

Figure 2 illustrates the relationship between gross and net monthly labour earnings as well as disposable income for a single person without children. Disposable income in the pre-reform situation (curve "Status Quo") starts at $€ 600$, which is the social assistance level for this household type. Benefits are phased out at a rate of approximately 80 per cent up to the break even income, where eligibility ends. ${ }^{6}$

\section{Reform scenario}

In our reform scenario, we fully abolish the basic social assistance rate for those welfare recipients who are considered to be able to work. Excepted from this requirement to work are individuals with more than one child (single parents and one of the spouses in couple households). To illustrate the reform scenario, the dashed line in Figure 2 ("Reform Scenario") depicts the new budget constraint for a single person without children. Here, benefits are cut by 50 per cent (from roughly $€ 600$ to $€ 300)$ and the transfer withdrawal rate is reduced to zero up to the net earnings

\footnotetext{
6 "15" and "30 hours" in Figure 2 refer to a weekly labour supply of a worker with a gross hourly wage of $€ 10.8$, which is the mean over all low-skilled individuals.
} 
level that is necessary to reach status-quo social assistance. In the example of Figure 2 , the individual may now earn $€ 300$ net labour income that is not withdrawn. Net earnings in excess of this amount are subject to a transfer withdrawal rate of 50 per cent up to the break even income where net income corresponds exactly to disposable income. In Figure 2, eligibility for social assistance extends up to net earnings of $€ 900$. Through the reform all positive working time categories become more attractive compared to non-participation due to the substantial reduction in the benefit level. In addition, the lower transfer-withdrawal rate may lead to a particular rise in disposable income for the lower working time categories. If this is the case, taking up a part-time job gains in attractiveness compared to a full-time job.

The transfer withdrawal rate for single individuals that are considered nonemployable remains the same as in the status-quo system, whereas for employable partners of non-employable persons in couple households it is lowered in the same way as for singles. For couple households with more than one child, benefit eligibility extends to considerably higher net earnings levels, e.g. with two children from $€ 1327$ in the status quo to $€ 1754$. The disincentives on female labour market participation are even increased, because the income range where additional female earnings lead to a loss in social assistance becomes larger. ${ }^{7}$

This welfare reform will in general not be revenue neutral. We warrant a constant level of publicly provided goods by adjusting the marginal income tax rate (on labour and domestic capital income). The sign of the necessary tax adjustment then tells us whether the welfare reform, in isolation, has a positive or negative revenue effect.

\subsection{Simulation results}

Table 1 shows the labour supply effects in our policy simulations. We group individuals both by household status (couples versus singles) and by skill type. Total labour supply (TLS) is further decomposed into the participation response (PR) and the change in hours of work, conditional on participation (AWT), i.e. the extensive versus the intensive margin. To put results into perspective, we compare the general equilibrium outcomes (left panel of Table 1) with the outcomes of a partial

\footnotetext{
${ }^{7}$ Here, it is important that social assistance entitlement is conditioned upon total household income.
} 
equilibrium setting, where both wages and unemployment rates are kept fixed (right panel). This is identical with the first iterative step in our linked model set-up. The second step then consists of running the general equilibrium model with this new labour supply level.

Table 1: Labour supply effects

\begin{tabular}{lcccccc}
\hline \hline Group & \multicolumn{3}{c}{ General equilibrium } & \multicolumn{3}{c}{ Partial labour } \\
model & & \multicolumn{3}{c}{ supply model } \\
\hline & PR & AWT & TLS & PR & AWT & TLS \\
\hline Men in couples & 1.39 & -0.18 & 1.20 & 1.97 & 0.00 & 2.02 \\
Women in couples & 0.42 & 0.03 & 0.64 & 1.00 & 0.20 & 1.65 \\
Singles & 4.68 & -1.62 & 4.08 & 5.41 & -1.12 & 5.50 \\
Low-skilled & 3.85 & -0.60 & 4.81 & 4.55 & -0.29 & 6.12 \\
Medium-skilled & 1.85 & -0.62 & 1.68 & 2.59 & -0.33 & 2.90 \\
High-skilled & 2.10 & -0.62 & 1.67 & 2.20 & -0.33 & 2.06 \\
All & 2.21 & -0.64 & 2.09 & 2.84 & -0.36 & 3.16 \\
\hline \hline
\end{tabular}

PR: participation rate (change in percentage points), AWT: average working time

(change in per cent), TLS: total labour supply in hours (change in per cent)

Labour supply responses in Table 1 are qualitatively identical in both model versions and can be summarised as follows:

- Participation goes up for all groups we distinguish, which is the direct effect of a reform that makes non-participation less attractive.

- Average working time slightly decreases, because in general the relative attractiveness of the low hours-of-work options increases. In couples, there are exceptions from this general pattern (most notably for married women), which are analysed in more detail in Arntz et al. (2008).

- The change in total labour supply, which combines participation and hoursof-work effects, is positive for all groups. The participation effect obviously dominates. 
- Classified by household type, labour supply effects are the strongest for singles, followed by married men and married women. This is not easily reconciled with the stylised fact that the labour supply elasticity of married women is higher than that of married men. However, incentive effects are intricate within couple households and because of income effects across partners, simulation results need not necessarily closely follow the labour supply elasticity patterns.

- The labour supply effect is the more pronounced the lower the skill level. This is what one would expect given that the reform is targeted towards the lower end of the labour market, and that the low skilled are most likely to have low incomes.

Comparing the left hand with the right hand panel of Table 1 shows that in general equilibrium the labour supply effect is considerably smaller than in partial equilibrium. This holds for all groups and at both margins of labour supply (lower participation and fewer hours of work). It is the consequence of the wage drops induced by the labour supply shock. Together with other aggregated labour market variables, these wage reactions are listed in Table 2 .

Table 2: Labour market general equilibrium effects

\begin{tabular}{lcccccc}
\hline \hline & \multicolumn{3}{c}{$\begin{array}{c}\text { Competitive market } \\
\text { for high skilled }\end{array}$} & \multicolumn{3}{c}{$\begin{array}{c}\text { Wage bargaining } \\
\text { for high skilled }\end{array}$} \\
& $\begin{array}{c}\text { Low } \\
\text { skilled }\end{array}$ & $\begin{array}{c}\text { Med. } \\
\text { skilled }\end{array}$ & $\begin{array}{c}\text { High } \\
\text { skilled }\end{array}$ & $\begin{array}{c}\text { Low } \\
\text { skilled }\end{array}$ & $\begin{array}{c}\text { Med. } \\
\text { skilled }\end{array}$ & $\begin{array}{c}\text { High } \\
\text { skilled }\end{array}$ \\
\hline Gross wage (\%) & -11.20 & -8.20 & -3.08 & -11.42 & -8.32 & -4.17 \\
$\quad$ average & & -7.24 & & & -7.78 & \\
Labour supply (\%) & 2.94 & 0.86 & 0.87 & 3.02 & 0.87 & 0.86 \\
$\quad$ average & & 1.09 & & & 1.10 & \\
Employment (\%) & 7.55 & 1.35 & 0.87 & 7.64 & 1.39 & 1.20 \\
$\quad$ average & & 1.82 & & & 1.94 & \\
Unempl. rate (p.p.) & -4.17 & -0.54 & - & -4.17 & -0.56 & -0.36 \\
$\quad$ average & & -0.91 & & & -0.99 & \\
Av. marg. tax (p.p.) & 2.68 & 1.76 & 1.07 & 2.66 & 1.77 & 1.10 \\
\hline \hline
\end{tabular}


The left panel of Table 2 is our main scenario, corresponding to the labour supply reactions in the left panel of Figure 1. This is compared to a model variant where the labour market regime for the high skilled is chosen identical to those of the other labour market segments, i.e. collective wage bargaining (right panel of Table 2). The table highlights some general effects of our reform scenario on the labour markets:

- On labour markets with collective wage bargaining (all cases except the high skilled in the left panel of Table 2), a reform that encourages labour supply exerts downward pressure on wages. Here three forces are at work. First, there is a direct effect of the increase in labour supply (as it would be on a competitive labour market). Second, the trade unions' fallback options deteriorate, since the cut in social assistance directly effects the expected income in the state of unemployment. Third, the reform increases average marginal tax rates because those who newly enter the phase-out region of social assistance (between $€$ 1000 and $€ 1300$ in Figure 2) dominate the average. This in turn leads to wage moderation (see Koskela and Vilmunen, 1996, for the general argument).

- The unemployment rate goes down, which is also an effect of the increase in the marginal tax rate. Consequently, the increase in employment even exceeds the positive labour supply reactions. ${ }^{8}$

To what extent do the model results depend on our assumption about the labour market regime for the high skilled? This can be seen by comparing the two panels of Table 2 .

- In general, the difference is most pronounced for the high skilled. This is what was to be expected, given that it is here where the change in the labour market regime directly applies. The spillover effects to the other segments of the labour market are small.

- With wage bargaining, the wages for the high skilled are lower, and employment is higher than in the version with a competitive labour market. This

\footnotetext{
${ }^{8}$ Differences in labour supply between Tables 1 and 2 have two reasons: In Table 1, labour supply is given in hours, whereas in Table 2 in efficient (wage-weighted) hours. Labour supply in Table 2 contains also the dampening effect of the dummy household with fixed labour supply.
} 
is because, in line with the general discussion above, two additional wagelowering effects enter: a deterioration of the fallback option for trade unions and higher tax progressivity.

Table 3: General equilibrium effects on macroeconomic variables

\begin{tabular}{lcc}
\hline \hline & $\begin{array}{c}\text { Competitive market } \\
\text { for high skilled }\end{array}$ & $\begin{array}{c}\text { Wage bargaining } \\
\text { for high skilled }\end{array}$ \\
\hline VA share of labour (p.p.) & -3.66 & -3.86 \\
Interest rate (\%) & 11.20 & 11.82 \\
Aggregate consumption (\%) & 1.31 & 1.40 \\
Aggregate investment (\%) & 1.69 & 1.81 \\
GDP (\%) & 1.08 & 1.16 \\
Income tax adjustment (p.p.) & 0.37 & 0.38 \\
\hline \hline
\end{tabular}

The characteristic traits of the labour market outcomes highlighted in Table 2 are reflected in a number of macroeconomic indicators, which are listed in Table 3 . The wage drops of Table 2 translate into a lower wage bill, because labour demand elasticities are relatively low and the increase in employment is not sufficient to compensate. This means a lower value-added share of labour ( -3.7 p.p.) and a considerably higher interest rate. ${ }^{9}$ The interest rate change induces a shift from consumption to investment. Finally, higher employment leads to an increase in GDP $(+1.1 \%)$. Interestingly, in spite of this GDP gain, the reform is not self-financing; we need a budget-balancing increase in the general income tax of 0.4 percentage points. The tax on capital income is lower than on labour (particularly so because we include social security contributions in the latter). This means that with a shift in functional income distribution in favour of capital income, total tax revenue falls and makes a compensatory tax rate increase necessary.

\footnotetext{
${ }^{9}$ Observe that the change in the interest rate is given in per cent, not in percentage points.
} 


\section{$5 \quad$ Sensitivity analysis}

\subsection{A different approach to labour demand calibration}

We have invested considerable effort in the calibration of the NNCES function to empirically estimated labour demand elasticities. Nevertheless, there remains an irreducible amount of arbitrariness, because we calibrate the function to a situation where value shares are different from the sample means in the estimation (see Appendix A.4).

The detailed tables of the labour demand elasticities per sector in Appendix A.4 are useful for assessing the accurateness of the calibration. However, we can easily get lost in the large number of different elasticity values. Therefore we try to find a small number of aggregate indicators that simplify comparisons across model versions. Table 4 presents a set of macroeconomic own and cross price elasticities. These have been generated by counterfactual model simulations where we exogenously increase the real wage of each skill group in turn, and report the employment change, including all general equilibrium reactions, but holding labour supply fixed. ${ }^{10}$

The upper panel of Table 4 displays the elasticities generated in this way. The following patterns can be observed: (1) The own-price elasticity of the low skilled is considerably larger than for the two other groups. (2) Cross price elasticities are in general small, except for a significant substitution effect of the medium-skilled wage on the demand for the low skilled. (3) Medium and high-skilled labour are complements at this level of aggregation and general equilibrium feedback.

The elasticities in Table 4 allow us to decompose the general equilibrium reaction from Table 2 into own and cross-price effects (see Table 5). In the row "Full equilibrium effect", we have the implicit general equilibrium elasticity that results from dividing the relative labour demand change by the relative wage change. Below in the "Partial effects" rows, we see the partial effects that result from combining the elasticities in Table 4 with the respective wage changes. ${ }^{11}$ Row "sum" adds up

\footnotetext{
${ }^{10}$ Strictly speaking, we have used the model version with wage bargaining for all three skill groups, because only in this case we can exogenously vary the wage rate.

${ }^{11}$ As a reading example, take the entry in the row "Medium skilled" and column "Low skilled". Wages of the medium skilled go down by $8.2 \%$ (Table 2) and produce a cross price effect of
} 
Table 4: Aggregated labour demand elasticities

\begin{tabular}{cccc}
\hline \hline & Low skilled & Medium skilled & High skilled \\
\hline Main model version & & & \\
Low skilled & -1.16 & 0.70 & 0.09 \\
Medium skilled & 0.08 & -0.27 & -0.02 \\
High skilled & 0.02 & -0.04 & -0.26 \\
Alternative calibration & & & \\
Low skilled & -1.23 & 0.70 & 0.06 \\
Medium skilled & 0.08 & -0.18 & -0.03 \\
High skilled & 0.02 & -0.06 & -0.15 \\
\hline \hline
\end{tabular}

Per cent effect on labour demand of type (row) from one per cent higher wage for type (column).

the partial effects, which turn out to be a reasonably close approximation of the general equilibrium effect. Own price effects dominate, but there is a considerably negative feedback going on between the low and the medium skilled.

In the labour demand calibration of our main version, we have put special weight on the own price elasticities (see Appendix A.4). Table 5 confirms that they quantitatively dominate the model outcomes, even if there are feedback effects from the other labour market segments. The trade-off that we accepted in this choice is that cross-price elasticities are less accurately reproduced. As a sensitivity check, we run the labour demand calibration without any weighting, so that own and cross price elasticities are equally important. The lower panel of Table 4 reports the consequences for the aggregated labour demand elasticities, and Table 6 displays the most important general equilibrium labour market variables in our policy scenario (compared to the values from the main model variant, reproduced from Table 2).

The changes both in the elasticities and in the policy simulation results remain within narrow bounds. As to the elasticities in Table 4, the contrast between the low

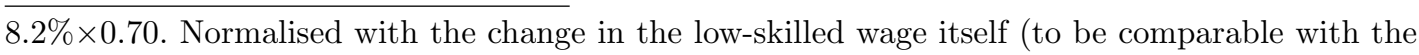
own-price elasticity), this gives an effect of 0.51 . 
Table 5: Labour demand elasticities: decomposition

\begin{tabular}{lccc}
\hline \hline & $\begin{array}{c}\text { Low } \\
\text { skilled }\end{array}$ & $\begin{array}{c}\text { Medium } \\
\text { skilled }\end{array}$ & $\begin{array}{c}\text { High } \\
\text { skilled }\end{array}$ \\
\hline $\begin{array}{l}\text { Elasticities } \\
\text { Full equilibrium effect }\end{array}$ & $\frac{7.55}{-11.20}=-0.67$ & $\frac{1.35}{-8.20}=-0.17$ & $\frac{0.87}{-3.08}=-0.28$ \\
Partial effects & & & \\
$\quad$ Low skilled & -1.16 & $\frac{-11.20 \times 0.08}{-8.20}=0.11$ & $\frac{-11.20 \times 0.02}{-3.08}=0.07$ \\
$\quad$ Medium skilled & $\frac{-8.20 \times 0.70}{-11.20}=0.51$ & -0.27 & $\frac{-8.20 \times-0.04}{-3.08}=-0.11$ \\
$\quad$ High skilled & $\frac{-3.08 \times 0.09}{-11.20}=0.03$ & $\frac{-3.08 \times-0.02}{-8.20}=-0.01$ & -0.26 \\
& -0.62 & -0.17 & -0.29 \\
\hline \hline
\end{tabular}

skilled and the other two skill groups becomes even more pronounced. Interestingly, it is the own-price elasticities that change, whereas the cross-price elasticities remain virtually unchanged. This backs up our choice of the weighted calibration as main variant: Weighting leads to a better fit for the own-price elasticities, while it does not considerably distort the off-diagonal terms (at least not in the aggregate).

\subsection{International capital mobility}

Labour demand elasticities have turned out to be a cornerstone for the explanation of the simulation results. It is difficult to pin down how precisely the elasticities generated in the model can be compared to empirical macro labour demand elasticities, ${ }^{12}$ but contrasting the values in Table 4 with the estimations of, for instance, Symons and Layard (1984) shows that the labour demand reactions in the model

\footnotetext{
${ }^{12}$ This is because empirical estimates are in most cases not perfectly clear as to which adjustment processes are endogenous and which are exogenous.
} 
Table 6: Sensitivity analysis 1: Alternative labour demand calibration

\begin{tabular}{lcc}
\hline \hline & $\begin{array}{c}\text { Main model } \\
\text { version }\end{array}$ & $\begin{array}{c}\text { Alternative } \\
\text { LD calibration }\end{array}$ \\
\hline Low skilled & & \\
Gross wage (\%) & -11.20 & -11.34 \\
Employment (\%) & 7.55 & 7.56 \\
Medium skilled & & \\
Gross wage (\%) & -8.20 & -9.85 \\
Employment (\%) & 1.35 & 0.92 \\
High skilled & & \\
Gross wage (\%) & -3.08 & -2.57 \\
Employment (\%) & 0.87 & 0.86 \\
Aggregate consumption (\%) & 1.31 & 1.05 \\
Aggregate investment (\%) & 1.69 & 1.49 \\
GDP (\%) & 1.08 & 0.90 \\
Income tax adjustment (p.p.) & 0.37 & 0.75 \\
\hline \hline
\end{tabular}

are lower than what one could have expected.

These relatively low labour demand elasticities show up at different places in the interpretation of the model results: (1) Changes in labour supply produce large shifts in the wage. (2) Wage changes dominate employment changes in the determination of total labour income. (3) This, in turn, bears on the aggregate tax revenue effect and the budget balancing tax adjustment, as we have seen in Section 4.2.

In addition to the labour demand estimates used, there is one additional assumption of the basic model version of Sections 4 and 5.1 that plays an important role here. Namely, capital is internationally immobile and the capital stock does not adjust to changes in the interest rate. This can be justified in a medium-run perspective, because labour market adjustment can reasonably be seen as faster than capital stock changes. However, at least in the long run, the total amount of capital used in the economy adjusts as well, either through internal savings or capital imports. 
We therefore complement the basic version with a variant where capital is mobile internationally, although not perfectly so. We calibrate the model to a capital import ratio of 0.18 (French and Poterba, 1991) and an elasticity of capital imports with respect to the domestic interest rate of 2.4 (de Mooij and Ederveen, 2001), so that a one per cent increase in the domestic interest rate goes along with a 0.43 per cent increase of the domestic capital stock. ${ }^{13}$ The consequences of this change for the labour demand elasticities can be seen in the lower part of Table $7 .{ }^{14}$ As expected, all own-price elasticities increase in absolute value. The changes are in proportion with the value shares of the different skill types: the highest for the medium skilled, the lowest for the low skilled (see Table 10 in the appendix for the value shares). In addition, the three skill types become more complementary over the board. An increase of the wage of any of the skill types drives capital out of the country, which lowers demand for the other two skills as well.

Table 7: Capital mobility and labour demand elasticities

\begin{tabular}{cccc}
\hline \hline & Low skilled & Medium skilled & High skilled \\
\hline Immobile capital & & & \\
Low skilled & -1.16 & 0.70 & 0.09 \\
Medium skilled & 0.08 & -0.27 & -0.02 \\
High skilled & 0.02 & -0.04 & -0.26 \\
Mobile capital & & & \\
Low skilled & -1.22 & 0.17 & -0.12 \\
Medium skilled & 0.02 & -0.76 & -0.22 \\
High skilled & -0.03 & -0.46 & -0.43 \\
\hline \hline
\end{tabular}

Per cent effect on labour demand of type (row) from one per cent higher wage for type (column).

The consequences of internationally mobile capital for the outcomes of the policy

\footnotetext{
${ }^{13}$ We also experimented with a version where capital is perfectly mobile internationally. However, this model variant does not allow to calculate labour demand elasticities as in Table 4, because with international mobile capital, we cannot fix all wages exogenously.

${ }^{14}$ The upper part reproduces Table 4 for comparison.
} 
scenario can be seen in Table 8. The stimulation of labour supply now leads to an increase in the domestic capital stock (1.81\%), while the change in the interest rate is more moderate. For all skill groups, both wages and employment levels are higher than in the version with immobile capital. The change is most remarkable for the high skilled. They now experience an increase in their wage and employment at the same time, which is a result of the stimulation of the two other labour markets. The macroeconomic changes are straightforward: Capital inflow leads to a higher GDP, and higher labour demand elasticities mean that the drop in the value share of labour is smaller. Both these effects contribute to higher tax revenue compared to the case with mobile capital, which turns the budget-balancing tax adjustment from positive to negative. The policy reform is now more than self-financing.

Table 8: Sensitivity analysis 2: Intenational capital mobility

\begin{tabular}{lcc}
\hline \hline & $\begin{array}{c}\text { Immobile } \\
\text { capital }\end{array}$ & $\begin{array}{c}\text { Mobile } \\
\text { capital }\end{array}$ \\
\hline Low skilled & & \\
Gross wage (\%) & -11.20 & -7.52 \\
$\quad$ Employment (\%) & 7.55 & 9.09 \\
Medium skilled & & \\
$\quad$ Gross wage (\%) & -8.20 & -3.55 \\
$\quad$ Employment (\%) & 1.35 & 2.25 \\
High skilled & & \\
$\quad$ Gross wage (\%) & -3.08 & 1.72 \\
$\quad$ Employment (\%) & 0.87 & 1.15 \\
Interest rate (\%) & 11.20 & 3.88 \\
Domestic capital use (\%) & - & 1.81 \\
GDP (\%) & 1.08 & 2.23 \\
Income tax adjustment (p.p.) & 0.37 & -1.13 \\
\hline \hline
\end{tabular}




\section{Conclusions}

We explore the consequences of implementing heterogeneous labour markets in a consistently linked micro-macro model used to analyse tax and transfer reforms. Three skill types of labour are distinguished, which are imperfect substitutes in the production process. They are implemented in a set-up that uses non-separable, nested CES functions in order to allow for an unrestricted matrix of elasticities of substitution within the production function. We combine wage bargaining for the low and medium skilled with a perfectly competitive labour market for the high skilled. Both the flexible substitution structure and the heterogeneity in labour market institutions play a role in the results, but labour demand elasticities turn out to be the most important drivers. This is because cross-price effects significantly modify the own-price effects, particularly as a spill-over from the medium-skilled to the low-skilled market segment.

We use the model to simulate a reform of the German transfer system that stimulates labour supply at the lower end of the wage distribution by combining lower basic social assistance payments and a lower transfer withdrawal rate. Qualitatively, the results are fairly robust. In all model variants considered, participation effects are positive and considerably large. They are most pronounced for singles; spouses in couples are less affected. In contrast, the effects on the average working time are small, so that changes in overall labour supply are dominated by the participation response.

In general equilibrium, wages fall for all skill groups, but most significantly for the low skilled. This produces feedback and dampens labour supply reactions compared to a partial analysis. Due to relatively low labour demand elasticities, wage drops translate into a lower share of labour, which in turn produces a switch in the spending pattern from consumption to investment. Although GDP increases by more than one percent, the welfare reform, in isolation, is not self-financing because the shift in functional income distribution causes considerable tax revenue losses.

The consequences of the switch from wage bargaining to competitive wage formation for the high skilled are concentrated on this very skill group. In a competitive labour market setting, the wage-reducing effects of higher tax progressivity and a 
deterioration of the fallback position of trade unions are absent. Therefore wage drops are less pronounced and employment gains are lower compared with collective wage bargaining.

A sensitivity analysis shows the importance of the assumptions about capital mobility for the results. In a model variant where we replace internationally immobile by mobile capital, labour demand elasticities are higher. This leads to an attenuation of the wage cuts as a consequence of the welfare reform. Both inflowing capital and a higher aggregate wage bill lead to higher tax revenue, which makes the welfare reform self-financing and allows the government to recycle additional tax revenue through a general cut in the income tax.

In the context of one concrete, stylised policy reform, our results show that the treatment of heterogeneous labour in economic models matters. Feedback and interaction effects turn out to be relevant, which produces a strong case for more heterogeneous and richer models. In particular, the labour-demand cross-price elasticities between the low and medium skilled are the main drivers of the results. Interaction with the high-skilled segment is less pronounced. In this setting, a careful sensitivity becomes crucial, because otherwise the complex interaction of effects cannot be disentangled anymore.

There are other fields of labour market analysis where heterogeneity in skill levels, labour market institutions and sectoral labour demand are relevant, and where therefore a complexity level such as the one in our model is required. The labour market consequences of sectoral changes in the trade structure and skill-specific migration policies are possible further applications of our model. 


\section{References}

Aaberge, Rolf, Ugo Colombino, Erling Holmøy, Birger Strøm and Tom Wennemo (2004): Population ageing and fiscal sustainability: an integrated micro-macro analysis of required tax changes, Discussion Paper No. 367, Statistics Norway.

Arntz, Melanie, Stefan Boeters and Nicole Gürtzgen (2006): Alternative approaches to discrete working time choice in an AGE framework, Economic Modelling 23, 1008-1023.

Arntz, Melanie, Stefan Boeters, Nicole Gürtzgen and Stefanie Schubert (2008): Analysing welfare reform in a microsimulation-AGE Model: The value of disaggregation, Economic Modelling 25, 422-439.

Ballard, Charles L., Don Fullerton, John B. Shoven and John Whalley (1985): A general equilibrium model for tax policy evaluation, The University of Chicago Press, National Bureau of Economic Research, Chicago.

Bargain, Olivier, Marco Caliendo, Peter Haan and Kristian Orsini (2005): 'Making work pay' in a rationed labour market: The Mini-Job reform in Germany, DIW Discussion Paper 536, Berlin.

Böhringer, Christoph, Stefan Boeters and Michael Feil (2005): Taxation and unemployment: an applied general equilibrium approach for Germany, Economic Modelling 22, 81-108.

Bourguignon, François, Anne-Sophie Robilliard and Sherman Robinson (2005): Representative versus real households in the macroeconomic modeling of inequality, in: Kehoe, T.E., T.N. Srinivasan and Whally, J. (ed.): Frontiers in applied general equilibrium modeling, Cambridge University Press, 219-254.

Buslei, Hermann and Viktor Steiner (1999): Beschäftigungseffekte von Lohnsubventionen im Niedriglohnbereich, Nomos, Baden-Baden.

Cororaton, Caesar B. and John Cockburn (2007): Trade reform and poverty Lessons from the Philippines: A CGE-microsimulation analysis, Journal of Policy Modeling, 29, 141-163.

Creedy, John and Guyonne Kalb (2005): Discrete hours labour supply modelling: specification, estimation and simulation, Journal of Economic Surveys 19, 697734. 
Duncan, Alan and Melvin Weeks (1998): Simulating transitions using discrete choice models, Papers and Proceedings of the American Statistical Association 106, 151-156.

Falk, Martin and Bertrand Koebel (1997): The demand of heterogeneous labour in Germany, ZEW Discussion Paper 97-28, Mannheim.

Falk, Martin and Bertrand Koebel (2001): A dynamic heterogeneous labour demand model for German manufacturing, Applied Economics 33, 330-348.

Fallon, Peter R. and Richard Layard (1975): Capital-skill complementarity, income distribution, and output accounting, Journal of Political Economy 83, 279-302.

Fitzenberger, Bernd (1999): Wages and employment across skill groups, ZEW Economic Studies, No. 6, Heidelberg: Physica.

Franz, Wolfgang, Nicole Gürtzgen, Stefanie Schubert and Markus Clauss (2007), Reformen im Niedriglohnsektor - eine integrierte CGE-Mikrosimulationsstudie der Arbeitsangebots- und Beschäftigungseffekte, ZEW Discussion Paper 07085, Mannheim.

French, Kenneth R. and James M. Poterba (1991): Investor diversification and international equity markets, American Economic Review, 81, 222-226.

Gelauff, George M.M. and Arjan M. Lejour (2006): Five Lisbon highlights - The economic impact of reaching these targets, CPB Document 104, Den Haag.

Graafland, Johan J., Ruud A. de Mooij, André G.H. Nibbelink and Ate Nieuwenhuis (2001): MIMICing tax policies and the labour market, Elsevier, Amsterdam.

Gupta, Anil and Vishnu Kapur (ed.) (2000): Microsimulation in government policy and forecasting, Elsevier, Amsterdam.

Hutton, John P. and Anna Ruocco (1999): Tax reform and employment in Europe, International Tax and Public Finance 6, 263-287.

IAB - Institut für Arbeitsmarkt- und Berufsforschung (2002): IAB-Zahlenfibel Ergebnisse der Arbeitsmarkt- und Berufsforschung in Tabellen, Nürnberg.

Koskela, Erkki and Jouko Vilmunen (1996): Tax progression is good for employment in popular models of trade union behaviour, Labour Economics 3, 65-80. 
McFadden, Daniel (1974): Conditional logit analysis of qualitative choice behavior, in: P. Zarembka (ed.), Frontiers in Econometrics, New York: Academic Press, 105-142.

de Mooij, Ruud A. and Sjef Ederveen (2001): Taxation and foreign direct investment, a synthesis of empirical research, CPB Netherlands Bureau for Economic Policy Analysis, Discussion Paper No. 003.

Müller, Tobias (2004): Evaluating the economic effects of income security reforms in Switzerland: an integrated microsimulation-computable general equilibrium approach, Working Paper, University of Geneva.

Orsini, Kristian (2005): The 2001 Belgian tax reform: equity and efficiency, Discussion Paper 05.04, Center for Economic Studies, University of Leuven.

Perroni, Carlo and Thomas F. Rutherford (1995): Regular flexibility of nested CES functions, European Economic Review 39, 335-343.

Perroni, Carlo and Thomas F. Rutherford (1998), Comparison of the performance of flexible functional forms for use in applied general equilibrium modelling, Computational Economics 11, 245-263.

Pissarides, Christopher A. (1990): Equilibrium unemployment theory, Basil Blackwell, Oxford.

Pollak, Robert A. and Terence J. Wales (1987): Specification and estimation of nonseparable two-stage technologies: The Leontief CES and the Cobb-Douglas CES, Journal of Political Economy 95, 311-333.

Rutherford, Thomas F., David Tarr and Oleksandr Shepotylo (2005): Poverty effects of Russia's WTO accession: modeling "real" households and endogenous productivity effects, World Bank Policy Research Working Paper 3473.

Shoven, John B. and John Whalley (1984): Applied general-equilibrium models of taxation and international trade: an introduction and survey, Journal of Economic Literature 22, 1007-1051.

van Soest, Arthur (1995): Structural models of family labor supply: a discrete choice approach, Journal of Human Resources 30, 63-88.

Symons, James and Richard Layard (1984): Neoclassical demand for labour functions for six major economies, Economic Journal 94, 788-799. 


\section{Appendix}

\section{A.1 Descriptive statistics}

Table 9: Discrete weekly working hours by household types

\begin{tabular}{lllllll}
\hline \hline Individual & \multicolumn{5}{c}{ Hours } & \multicolumn{3}{c}{ Options } \\
\hline men, married or single without children & 0 & & & 38 & 49 \\
men, single with children & 0 & 15 & 30 & 38 & 49 \\
women, single & 0 & 15 & 30 & 38 & 49 \\
women, married & 0 & 9.5 & 24 & 38 & 47 \\
\hline \hline
\end{tabular}

Table 10: Characteristics of skill groups in SOEP

\begin{tabular}{lcccc}
\hline \hline & $\begin{array}{c}\text { Low } \\
\text { skilled* }\end{array}$ & $\begin{array}{c}\text { Medium } \\
\text { skilled }\end{array}$ & $\begin{array}{c}\text { High } \\
\text { skilled* }\end{array}$ & All \\
\hline Number of individuals & 854 & 3016 & 761 & 4631 \\
$\quad$ Share in dataset, unweighted (\%) & 18.44 & 65.13 & 16.43 & 100.00 \\
$\quad$ Share in dataset, weighted (\%) & 15.82 & 68.24 & 15.94 & 100.00 \\
Singles & & & & \\
$\quad$ Share in skill group, weighted (\%) & 38.16 & 32.88 & 37.96 & 34.52 \\
Women in couples & & & & 32.74 \\
$\quad$ Share in skill group, weighted (\%) & 37.49 & 33.89 & 23.09 & 32.74 \\
Men in couples & & & & \\
$\quad$ Share in skill group, weighted (\%) & 24.35 & 33.23 & 38.95 & \\
Participation & & & & \\
$\quad$ Participation rate, weighted (\%) & 70.71 & 79.97 & 91.25 & 80.30 \\
$\quad$ Share in total participation, weighted (\%) & 13.93 & 67.95 & 18.12 & 100.00 \\
Average hours per worker, weighted & 35.55 & 37.55 & 39.87 & 37.69 \\
$\quad$ Share in total hours, weighted (\%) & 13.14 & 67.70 & 19.16 & 100.00 \\
Average gross wage per hour, weighted (€) & 11.70 & 13.38 & 18.37 & 14.12 \\
$\quad$ Share in total wage bill, weighted (\%) & 10.89 & 64.17 & 24.93 & 100.00 \\
\hline \hline
\end{tabular}

*"Low skilled": no finished formal education, "high skilled": finished tertiary education 


\section{A.2 Estimation results from the microsimulation model}

Table 11: Maximum likelihood estimates for single females

\begin{tabular}{|c|c|c|c|c|}
\hline & Coef. & SE & $\mathrm{z}$ & $\mathrm{P}>\mathrm{z}$ \\
\hline Net household income & -6.44 & 1.85 & -3.48 & 0.001 \\
\hline Net household income^2 & 0.43 & 0.08 & 5.22 & 0.000 \\
\hline Net hh income $\mathrm{X}$ leisure & 0.48 & 0.30 & 1.63 & 0.103 \\
\hline Leisure X East Germany & -0.96 & 0.29 & -3.32 & 0.001 \\
\hline Leisure X nationality & 0.23 & 0.41 & 0.57 & 0.566 \\
\hline Leisure & 77.59 & 14.10 & 5.50 & 0.000 \\
\hline Leisure^2 & -9.96 & 1.80 & -5.55 & 0.000 \\
\hline Leisure $\mathrm{X}$ age & -1.11 & 0.31 & -3.65 & 0.000 \\
\hline Leisure $X$ age^2 & 0.10 & 0.04 & 2.42 & 0.016 \\
\hline Leisure^2 $\mathrm{X}$ age & 0.59 & 0.12 & 4.83 & 0.000 \\
\hline Leisure X handicapped & -0.17 & 0.90 & -0.18 & 0.853 \\
\hline Leisure $\mathrm{X}$ children $<6$ years & 4.99 & 0.60 & 8.32 & 0.000 \\
\hline Leisure $\mathrm{X}$ children $7-16$ years & 1.50 & 0.35 & 4.29 & 0.000 \\
\hline Leisure $\mathrm{X}$ children $>=17$ years & -0.48 & 0.31 & -1.53 & 0.127 \\
\hline Dummy for employment & -2.13 & 0.25 & -8.67 & 0.000 \\
\hline Number of obs. & \multicolumn{4}{|c|}{540} \\
\hline Log Likelihood & \multicolumn{4}{|c|}{-636.0} \\
\hline
\end{tabular}


Table 12: Maximum likelihood estimates for single males

\begin{tabular}{lrrrr}
\hline \hline & \multicolumn{1}{c}{ Coef. } & \multicolumn{1}{l}{ SE } & \multicolumn{1}{c}{$\mathrm{z}$} & $\mathrm{P}>\mathrm{z}$ \\
\hline Net household income & 6.76 & 2.73 & 2.48 & 0.013 \\
Net household income`2 & -0.019 & 0.10 & -0.19 & 0.848 \\
Net hh income X leisure & -1.42 & 0.44 & -3.21 & 0.001 \\
Leisure & 169.71 & 20.03 & 8.47 & 0.000 \\
Leisure`2 $^{\wedge}$ & -21.13 & 2.60 & -8.12 & 0.000 \\
Leisure X East Germany & -0.05 & 0.33 & -0.15 & 0.881 \\
Leisure X nationality & 0.29 & 0.48 & 0.60 & 0.547 \\
Leisure X age & -0.74 & 0.32 & -2.34 & 0.019 \\
Leisure X age`2 & 0.41 & 0.12 & 3.35 & 0.001 \\
Leisure`2 X age & 0.06 & 0.04 & 1.46 & 0.143 \\
Leisure X handicapped & 1.32 & 0.83 & 1.60 & 0.110 \\
Dummy for employment & -9.96 & 1.13 & -8.78 & 0.000 \\
\hline Number of obs. & \multicolumn{5}{c}{952} \\
Log Likelihood & -1286.7 \\
\hline \hline Conditionl logit with five
\end{tabular}

Conditional logit with five hours-of-work options $(0,15$, 30, 38, 49), SOEP 1999 
Table 13: Maximum likelihood estimates for couples

\begin{tabular}{|c|c|c|c|c|}
\hline & Coef. & SE & $\mathrm{z}$ & $\mathrm{P}>\mathrm{z}$ \\
\hline Net household income & 8.95 & 5.11 & 1.75 & 0.080 \\
\hline Net household income`2 & -0.003 & 0.26 & -0.01 & 0.989 \\
\hline Net hh income $\mathrm{X}$ leisure of male spouse & -1.46 & 0.42 & -3.46 & 0.001 \\
\hline Net hh income $\mathrm{X}$ leisure of female spouse & -0.43 & 0.38 & -1.14 & 0.253 \\
\hline Net hh income $\mathrm{X}$ nationality & -6.92 & 3.82 & -1.81 & 0.070 \\
\hline Net hh income^2 X nationality & 0.56 & 0.27 & 2.09 & 0.036 \\
\hline Net hh income X East Germany & 5.50 & 1.87 & 2.94 & 0.003 \\
\hline Net hh income^ $2 \mathrm{X}$ East Germany & -0.49 & 0.14 & -3.37 & 0.001 \\
\hline Leisure of male spouse & 56.72 & 7.15 & 7.94 & 0.000 \\
\hline Leisure of male spouse^2 & -4.06 & 0.47 & -8.66 & 0.000 \\
\hline Leisure of male spouse $\mathrm{X}$ nationality & -0.40 & 0.41 & -0.98 & 0.328 \\
\hline Leisure of male spouse X East Germany & -6.05 & 2.80 & -2.16 & 0.031 \\
\hline Leisure of male spouse $\mathrm{X}$ age & -0.36 & 0.08 & -4.31 & 0.000 \\
\hline Leisure of male spouse $\mathrm{X}$ age ${ }^{\wedge} 2$ & 0.48 & 0.10 & 4.99 & 0.000 \\
\hline Leisure of male spouse X handicapped & 0.76 & 0.72 & 1.06 & 0.290 \\
\hline Leisure of female spouse & 79.98 & 7.00 & 11.43 & 0.000 \\
\hline Leisure of female spouse ${ }^{\wedge} 2$ & -8.40 & 0.53 & -15.77 & 0.000 \\
\hline Leisure of female spouse $\mathrm{X}$ nationality & 0.27 & 0.40 & 0.67 & 0.501 \\
\hline Leisure of female spouse X East Germany & -7.10 & 2.59 & -2.74 & 0.006 \\
\hline Leisure of female spouse $\mathrm{X}$ age & -0.39 & 0.09 & -4.18 & 0.000 \\
\hline Leisure of female spouse $\mathrm{X}$ age`2 & 0.58 & 0.11 & 5.26 & 0.000 \\
\hline Leisure of female spouse X handicapped & 0.97 & 0.71 & 1.36 & 0.175 \\
\hline Leisure of female spouse $\mathrm{X}$ children $<6$ years & 4.63 & 0.31 & 14.98 & 0.000 \\
\hline Leisure of female spouse $\mathrm{X}$ children $7-16$ years & 2.13 & 0.22 & 9.59 & 0.000 \\
\hline Leisure of female spouse $\mathrm{X}$ children $>=17$ years & -0.56 & 0.22 & -2.56 & 0.011 \\
\hline Leisure of male spouse $\mathrm{X}$ Leisure of female spouse & -1.50 & 0.55 & -2.72 & 0.006 \\
\hline Leisure of male spouse & & & & \\
\hline $\mathrm{X}$ Leisure of female spouse $\mathrm{X}$ nationality & 0.26 & 0.14 & 1.78 & 0.075 \\
\hline Leisure of male spouse & & & & \\
\hline X Leisure of female spouse X East Germany & 1.03 & 0.70 & 1.47 & 0.142 \\
\hline Dummy for employment of female spouse & -2.55 & 0.25 & -10.09 & 0.000 \\
\hline Dummy for employment of both spouses & 0.61 & 0.24 & 2.54 & 0.011 \\
\hline Number of obs. & \multicolumn{4}{|c|}{1910} \\
\hline Log Likelihood & \multicolumn{4}{|c|}{-4186.1} \\
\hline
\end{tabular}




\section{A.3 The budget constraint}

In the context of our discrete choice set-up, the budget constraint must be determined for the finite set of hours categories, based on the German tax-benefit-system. First, gross monthly earnings are obtained by multiplying the gross hourly wage with monthly hours of work corresponding to the respective category of weekly labour supply. Since gross hourly wages are unobserved for those not employed, wages have to be estimated using a Mincer-type wage regression with education, experience and some further controls (e.g. nationality, marital status). Variables for identifying the labour force status are the income of other household members and whether someone is handicapped.

To obtain net earnings per month, income taxes and social security contributions are deducted from gross monthly earnings. In general, we apply the tax and transfer rules of the year 2000. The share in social security contributions paid by employees amounts to 20 per cent of gross monthly earnings exceeding $€ 325$. Income taxes are calculated on the basis of taxable income, which is obtained by subtracting a standard deduction from gross earnings. For couple households, income tax legislation allows for marital income splitting: According to this method, the tax schedule is applied to half of the joint taxable income, while the resulting tax amount is doubled to obtain total income taxes paid by the couple.

Finally, disposable monthly earnings are obtained by adding transfer payments to net earnings. We account for unemployment benefits and assistance, social assistance and child benefits, while housing benefits are neglected. In Germany, unemployment benefits (UB) are available for persons who have paid contributions to the statutory unemployment insurance for a minimum of one year. In particular, the duration of unemployment benefits depends on the unemployed person's former labour market experience and age. The monthly amount received equals a constant fraction of previous net monthly earnings. The replacement rate for persons without children is 60 per cent and for persons with children 67 per cent. Unemployment benefits are not means-tested. The entitlement to UB is thus completely independent from the labour or transfer income received by the respective spouse.

For those who do not have enough experience to obtain unemployment benefits or who have exhausted their unemployment benefits, unemployment assistance (UA) and social assistance (SA) become relevant. The replacement rate for UA payments for persons without children is 53 per cent and for persons with children 57 per cent. In contrast to unemployment benefits, both welfare payments are means-tested, i.e. payments are reduced if either the unemployed person or remaining household members receive other incomes. While UA is only available for those persons who 
have exhausted their unemployment benefits, eligibility for SA does not require any former entitlement to unemployment benefits. Our model takes into account the means-tested nature of SA payments, but neglects the means-tested nature of UA payments.

If labour supply is zero hours (voluntary unemployment), no unemployment compensation is assigned. Each positive labour supply, in contrast, may result in three different labour market states: employment $(e)$, involuntary unemployment with unemployment compensation $(b)$, or involuntary unemployment with social assistance $(n)$. Owing to the static nature of the model, we are not able to determine whether or not a person is entitled to unemployment benefits. Instead, we assume that a weighted average of UB and UA replacement rates is paid with an exogenous probability $P_{U C}$. We assume $P_{U C}$ to be uniform across households; it equals the empirical share of unemployed persons receiving unemployment compensation (0.8 according to IAB, 2002). Unemployment compensation is determined on the basis of the chosen category of hours supplied and the effective replacement ratio. In a last step, supplemental social assistance is assigned based on earnings and other transfer income.

The distinction of three labour market states requires that the value of disposable income for a particular working time option is calculated as an expected value. We make the simplifying assumption that worker households do not save and use expected disposable income as a proxy for consumption. For singles, we generate the average of the disposable income, $y^{d}$, over the three labour market states with the respective probabilities, $P_{i, j}, i=e, b, n$, as weights:

$$
C_{j}\left(h_{j, k}\right)=E\left(y_{j}^{d}\left(h_{j, k}\right)\right)=\sum_{i=e, b, n} P_{i, j} y^{d}\left(h_{j, k}, i\right)
$$

(For the rest of the notation, see Section 2.1). In particular, we have $P_{e, j}=\left(1-u_{j}\right)$, $P_{b, j}=u_{j} P_{U C}$ and $P_{n, j}=u_{j}\left(1-P_{U C}\right)$, with $u_{j}$ representing (household type specific) unemployment rates. For couples, the expected disposable income is determined by the weighted average of disposable incomes over the 9 combinations of labour market states:

$$
C_{j}\left(h_{j, k}^{f}, h_{j, k}^{m}\right)=E\left(y_{j}^{d}\left(h_{j, k}^{f}, h_{j, k}^{m}\right)\right)=\sum_{i, g=e, b, n} P_{i, j} P_{g, j} y_{j}^{d}\left(h_{j, k}^{f}, h_{j, k}^{m}, i, g\right)
$$

In the policy simulations, we use a first-order approximation of the tax-transfer schedule. We disturb the calculations of disposable income marginally at all relevant points to calculate numerically the local effective marginal burden of the total taxtransfer system. 


\section{A.4 Details of the NNCES calibration}

In Table 14 we reproduce the estimation results of Falk and Koebel (1997) that underlay our NNCES calibration. Falk and Koebel estimate full $5 \times 5$ matrices of own and cross price elasticities for intermediate inputs (materials and energy) ("I"), low-skilled labour ("L"), medium-skilled labour ("M"), high-skilled labour ("H") and capital ("K") in five sectors: Energy and Mining ("E_M"), Manufacturing ("MAN"), Construction ("CON"), Trade and Transport ("T_T"), and Banking and Insurance ("B_I").

Through the symmetry requirement

$$
\frac{\eta_{i j}}{\theta_{j}}=\frac{\eta_{j i}}{\theta_{i}}
$$

and the share identity

$$
\sum_{i} \theta_{i}=1
$$

we can recover the underlying value shares, $\theta_{i}$. They are summarised in the upper part of Table 15. A complication arises through the fact that the value shares in the AGE model do not coincide with those implicit in the estimation. The lower part of Table 15 displays the value shares in PACE-L, including the two sectors for which no estimation of cross-price elasticities is available. The overall fit is reasonable, however, in PACE-L, the share of high-skilled labour is uniformly higher, and there seems to be a problem with the value share of capital in the financial intermediation sector. (Most probably, this latter problem is caused by the accounting of interest rate margins, a recurrent problem in the construction of IO tables.)

Combining the demand elasticities of Table 14 with the value shares of the lower part of Table 15 is not straightforward, because the identity (1) is violated with the new value shares $\bar{\theta}_{i}$. In the necessary adjustment, we must account both for the homogeneity of the demand functions,

$$
\sum_{j} \eta_{i j}=0
$$

and the negative semi-definiteness of the matrix of factor demand elasticities. We approach this problem by a least-squares optimisation, where we minimise the relative deviations of the calibrated from the estimated demand elasticities, taking symmetry, homogeneity and negative semi-definiteness as restrictions. In addition, we put special weight (by a factor of ten) on the own price elasticities, because we consider them of special importance for the simulation results. The outcome of the optimisation is given in Table 16. This table also includes the two sectors for 
Table 14: Cross price elasticities (estimation by Falk and Koebel, 1997)

\begin{tabular}{lrrrrr}
\hline \hline & E_M & MAN & CON & \multicolumn{1}{c}{ T_T $_{-}$B_I } \\
\hline$\eta_{I, I}$ & -0.038 & -0.006 & -0.107 & -0.001 & -0.012 \\
$\eta_{I, L}$ & -0.001 & 0.012 & 0.067 & -0.007 & 0.014 \\
$\eta_{I, M}$ & 0.014 & 0.023 & 0.019 & 0.012 & -0.010 \\
$\eta_{I, H}$ & 0.008 & -0.004 & 0.056 & -0.004 & 0.003 \\
$\eta_{I, K}$ & 0.022 & -0.004 & 0.015 & 0.001 & 0.005 \\
$\eta_{L, I}$ & -0.005 & 0.138 & 0.343 & -0.021 & 0.097 \\
$\eta_{L, L}$ & -0.256 & -1.409 & -1.049 & -0.052 & -1.244 \\
$\eta_{L, M}$ & 0.107 & 0.128 & 0.075 & 0.017 & 0.366 \\
$\eta_{L, H}$ & 0.222 & 1.062 & 0.422 & 0.042 & 0.789 \\
$\eta_{L, K}$ & -0.067 & 0.078 & 0.207 & 0.014 & -0.008 \\
$\eta_{M, I}$ & 0.115 & 0.010 & 0.038 & 0.022 & -0.021 \\
$\eta_{M, L}$ & 0.051 & 0.444 & 0.167 & 0.012 & 0.237 \\
$\eta_{M, M}$ & -0.174 & -0.481 & -0.118 & -0.022 & -0.206 \\
$\eta_{M, H}$ & -0.009 & 0.020 & -0.021 & 0.028 & -0.006 \\
$\eta_{M, K}$ & 0.017 & 0.006 & -0.067 & -0.015 & -0.010 \\
$\eta_{H, I}$ & 0.047 & -0.161 & 0.257 & -0.159 & 0.070 \\
$\eta_{H, L}$ & 0.186 & 0.472 & 0.677 & 0.115 & 1.196 \\
$\eta_{H, M}$ & -0.073 & 0.166 & -0.458 & 0.062 & -0.063 \\
$\eta_{H, H}$ & -0.170 & -0.418 & -0.697 & -0.126 & -1.226 \\
$\eta_{H, K}$ & 0.010 & -0.058 & 0.221 & 0.108 & 0.100 \\
$\eta_{K, I}$ & 0.094 & -0.041 & 0.178 & 0.043 & 0.021 \\
$\eta_{K, L}$ & -0.008 & 0.070 & 0.455 & 0.011 & -0.005 \\
$\eta_{K, M}$ & 0.009 & 0.013 & -0.375 & -0.037 & -0.021 \\
$\eta_{K, H}$ & 0.006 & -0.014 & 0.054 & 0.012 & 0.021 \\
$\eta_{K, K}$ & -0.095 & -0.027 & -0.313 & -0.029 & -0.015 \\
\hline \hline & & & & &
\end{tabular}


Table 15: Value shares of inputs in Falk and Koebel and PACE-L

\begin{tabular}{lccccccc}
\hline \hline & E_M & MAN & CON & T_T $_{-}$ & B_I & AGR & OSE \\
\hline \multicolumn{8}{c}{ Falk and Koebel $(1997)$} \\
$\theta_{I}$ & 0.708 & 0.663 & 0.552 & 0.592 & 0.527 & & \\
$\theta_{L}$ & 0.021 & 0.070 & 0.110 & 0.081 & 0.080 & & \\
$\theta_{M}$ & 0.090 & 0.168 & 0.276 & 0.245 & 0.265 & & \\
$\theta_{H}$ & 0.012 & 0.019 & 0.013 & 0.010 & 0.025 & & \\
$\theta_{K}$ & 0.169 & 0.079 & 0.050 & 0.073 & 0.102 & & \\
\hline \multicolumn{7}{c}{$P A C E-L$} \\
$\bar{\theta}_{I}$ & 0.514 & 0.679 & 0.551 & 0.421 & 0.353 & 0.515 & 0.318 \\
$\bar{\theta}_{L}$ & 0.012 & 0.030 & 0.034 & 0.030 & 0.005 & 0.015 & 0.031 \\
$\bar{\theta}_{M}$ & 0.182 & 0.182 & 0.258 & 0.328 & 0.120 & 0.132 & 0.276 \\
$\bar{\theta}_{H}$ & 0.092 & 0.075 & 0.037 & 0.060 & 0.065 & 0.068 & 0.230 \\
$\bar{\theta}_{K}$ & 0.200 & 0.033 & 0.119 & 0.161 & 0.457 & 0.270 & 0.145 \\
\hline \hline
\end{tabular}

which we do not have estimates, AGR and OSE. Here we have calculated the target elasticities as the output-weighted average of all other sectors. In some cases, the deviations between Tables 16 and 14 are considerable, including a few cases of sign reversals. This warrants some caution in interpreting the simulation results.

In the sensitivity analysis (Section 5.1), we also try another labour demand calibration, where we do not put special weight one the own price elasticities. The results of this calibration can be seen in Table 17 .

Table 18 gives an example (sector MAN) of the numerical results of the last step in the NNCES calibration described in Section 3.1 of the main text. The results of the other sectors vary according to the targeted labour demand elasticities, but some aspects can be observed in general:

- Often four sub-aggregates are sufficient for the calibration. Only in three of the seven sectors all five sub-aggregates are needed.

- The calibration procedure is reasonably efficient in concentrating the factors in the sub-aggregates. Low and medium-skilled labour only appears in one nest.

- The resulting pattern of elasticities is similar in all sectors. A high elasticity (above one) at the upper level is combined with very low elasticities (in most cases zero) at the lower level. This pattern is not necessary, but induced by both the starting values and the penalty function. 
Table 16: Cross price elasticities in PACE-L (least squares adjustment)

\begin{tabular}{lccccccc}
\hline \hline & E_M & MAN & CON & T_T & B_I & AGR & OSE \\
\hline$\eta_{I, I}$ & -0.045 & -0.006 & -0.105 & -0.002 & -0.012 & -0.018 & -0.018 \\
$\eta_{I, L}$ & -0.000 & 0.001 & 0.020 & 0.001 & 0.000 & -0.002 & -0.006 \\
$\eta_{I, M}$ & 0.018 & 0.005 & 0.026 & 0.001 & 0.011 & 0.007 & 0.015 \\
$\eta_{I, H}$ & 0.011 & 0.002 & 0.032 & 0.001 & 0.006 & 0.009 & 0.006 \\
$\eta_{I, K}$ & 0.016 & -0.002 & 0.027 & 0.000 & -0.005 & 0.004 & 0.003 \\
$\eta_{L, I}$ & -0.006 & 0.018 & 0.323 & 0.001 & 0.001 & -0.068 & -0.057 \\
$\eta_{L, L}$ & -0.264 & -1.630 & -1.071 & -0.097 & -1.389 & -1.196 & -1.202 \\
$\eta_{L, M}$ & 0.228 & 1.290 & 0.449 & 0.041 & 1.453 & 0.978 & 0.963 \\
$\eta_{L, H}$ & 0.128 & 0.259 & 0.079 & 0.034 & -0.056 & 0.247 & 0.246 \\
$\eta_{L, K}$ & -0.086 & 0.062 & 0.221 & 0.021 & -0.009 & 0.039 & 0.050 \\
$\eta_{M, I}$ & 0.051 & 0.018 & 0.055 & 0.001 & 0.033 & 0.026 & 0.017 \\
$\eta_{M, L}$ & 0.014 & 0.215 & 0.060 & 0.004 & 0.061 & 0.108 & 0.108 \\
$\eta_{M, M}$ & -0.121 & -0.326 & -0.116 & -0.037 & -0.103 & -0.162 & -0.161 \\
$\eta_{M, H}$ & 0.019 & 0.089 & -0.016 & 0.022 & 0.007 & 0.018 & 0.027 \\
$\eta_{M, K}$ & 0.036 & 0.003 & 0.018 & 0.011 & 0.003 & 0.011 & 0.009 \\
$\eta_{H, I}$ & 0.064 & 0.019 & 0.473 & 0.005 & 0.032 & 0.068 & 0.008 \\
$\eta_{H, L}$ & 0.016 & 0.105 & 0.073 & 0.017 & -0.004 & 0.053 & 0.033 \\
$\eta_{H, M}$ & 0.037 & 0.218 & -0.112 & 0.118 & 0.012 & 0.035 & 0.032 \\
$\eta_{H, H}$ & -0.140 & -0.339 & -0.690 & -0.206 & -0.174 & -0.288 & -0.085 \\
$\eta_{H, K}$ & 0.023 & -0.005 & 0.255 & 0.066 & 0.135 & 0.132 & 0.012 \\
$\eta_{K, I}$ & 0.040 & -0.038 & 0.126 & 0.001 & -0.004 & 0.008 & 0.006 \\
$\eta_{K, L}$ & -0.005 & 0.057 & 0.064 & 0.004 & -0.000 & 0.002 & 0.011 \\
$\eta_{K, M}$ & 0.033 & 0.018 & 0.038 & 0.021 & 0.001 & 0.005 & 0.017 \\
$\eta_{K, H}$ & 0.011 & -0.010 & 0.079 & 0.025 & 0.019 & 0.033 & 0.018 \\
$\eta_{K, K}$ & -0.079 & -0.027 & -0.307 & -0.051 & -0.016 & -0.049 & -0.053 \\
\hline \hline
\end{tabular}


Table 17: Cross price elasticities in PACE-L (sensitivity analysis)

\begin{tabular}{lccccccc}
\hline \hline & E_M & MAN & CON & T_T & B_I & AGR & OSE \\
\hline$\eta_{I, I}$ & -0.050 & -0.005 & -0.089 & -0.003 & -0.011 & -0.011 & -0.025 \\
$\eta_{I, L}$ & -0.000 & 0.008 & 0.025 & -0.001 & 0.002 & 0.004 & 0.010 \\
$\eta_{I, M}$ & 0.017 & 0.003 & 0.021 & 0.003 & -0.001 & 0.003 & 0.009 \\
$\eta_{I, H}$ & 0.009 & -0.004 & 0.023 & -0.001 & 0.004 & 0.001 & 0.003 \\
$\eta_{I, K}$ & 0.025 & -0.002 & 0.020 & 0.001 & 0.006 & 0.003 & 0.003 \\
$\eta_{L, I}$ & -0.006 & 0.181 & 0.398 & -0.010 & 0.118 & 0.135 & 0.105 \\
$\eta_{L, L}$ & -0.283 & -1.705 & -1.299 & -0.105 & -1.707 & -1.225 & -1.208 \\
$\eta_{L, M}$ & 0.255 & 1.294 & 0.571 & 0.072 & 1.098 & 0.859 & 0.867 \\
$\eta_{L, H}$ & 0.115 & 0.151 & 0.083 & 0.023 & 0.499 & 0.178 & 0.172 \\
$\eta_{L, K}$ & -0.082 & 0.079 & 0.247 & 0.021 & -0.008 & 0.053 & 0.063 \\
$\eta_{M, I}$ & 0.048 & 0.012 & 0.044 & 0.004 & -0.002 & 0.013 & 0.010 \\
$\eta_{M, L}$ & 0.016 & 0.215 & 0.076 & 0.006 & 0.046 & 0.095 & 0.097 \\
$\eta_{M, M}$ & -0.067 & -0.256 & -0.060 & -0.039 & -0.035 & -0.106 & -0.109 \\
$\eta_{M, H}$ & -0.010 & 0.026 & -0.021 & 0.022 & -0.005 & 0.008 & 0.010 \\
$\eta_{M, K}$ & 0.012 & 0.003 & -0.039 & 0.005 & -0.004 & -0.009 & -0.009 \\
$\eta_{H, I}$ & 0.048 & -0.036 & 0.343 & -0.009 & 0.021 & 0.011 & 0.005 \\
$\eta_{H, L}$ & 0.014 & 0.061 & 0.078 & 0.011 & 0.039 & 0.038 & 0.023 \\
$\eta_{H, M}$ & -0.019 & 0.063 & -0.149 & 0.122 & -0.009 & 0.016 & 0.012 \\
$\eta_{H, H}$ & -0.055 & -0.082 & -0.482 & -0.188 & -0.166 & -0.104 & -0.046 \\
$\eta_{H, K}$ & 0.011 & -0.007 & 0.210 & 0.064 & 0.115 & 0.040 & 0.006 \\
$\eta_{K, I}$ & 0.064 & -0.046 & 0.093 & 0.003 & 0.005 & 0.005 & 0.006 \\
$\eta_{K, L}$ & -0.005 & 0.072 & 0.071 & 0.004 & -0.001 & 0.003 & 0.013 \\
$\eta_{K, M}$ & 0.011 & 0.016 & -0.084 & 0.011 & -0.001 & -0.005 & -0.017 \\
$\eta_{K, H}$ & 0.005 & -0.015 & 0.065 & 0.024 & 0.016 & 0.010 & 0.010 \\
$\eta_{K, K}$ & -0.075 & -0.026 & -0.146 & -0.042 & -0.020 & -0.014 & -0.012 \\
\hline \hline
\end{tabular}


Table 18: NNCES calibration for sector "Manufacturing"

\begin{tabular}{lccccc}
\hline \hline & $(1)$ & $(2)$ & $(3)$ & $(4)$ & $(5)$ \\
\hline Share & 0.011 & 0.116 & 0.072 & 0.801 & - \\
Intermediates & 0.014 & 0.116 & 0.072 & 0.798 & - \\
Low skilled labour & - & 1.000 & - & - & - \\
Medium skilled labour & - & - & - & 1.000 & - \\
High skilled labour & - & 0.059 & 0.275 & 0.666 & - \\
Capital & 0.041 & 0.086 & 0.084 & 0.790 & - \\
$\sigma^{n}$ & 0.000 & 0.000 & 0.000 & 0.007 & - \\
$\sigma^{Y}$ & \multicolumn{7}{c}{7.072} \\
\hline \hline
\end{tabular}

